\title{
ВОЗДЕЙСТВИЕ ИННОВАЦИЙ И ИНФОРМАЦИОННЫХ ТЕХНОЛОГИЙ НА РЕГИОНАЛЬНУЮ ЭКОНОМИКУ
}

\author{
(c) 2018 Гарипова Екатерина Николаевна \\ ассистент кафедры общего менеджмента \\ Институт управления, экономики и финансов \\ Казанский (Приволжский) федеральный университет \\ 420008, Республика Татарстан, г. Казань, ул. Кремлевская, д. 18 \\ E-mail: garipova_e_n@list.ru
}

Исследование нацелено на разработку целостной имитации и методологического инструментария построения системной многосекторной диагностики проходящих в региональной экономике процессов, а также оценку взаимовлияния важнейших параметров, позволяющую объяснить природу «возмущений» в региональной экономике для обеспечения реализации эффективной и продуктивной экономической политики.

Ключевые слова: инновации, информационные технологии, рынок инноваций, рынок информационных технологий, взаимовлияние инноваций и информационных технологий, региональная экономика, рынок факторов производства, системная функциональная многосекторная модель рыночной экономики.

Современная экономическая среда характеризуется сверхвысокой турбулентностью, возникновением новых межрыночных связей, требующих детального рассмотрения. Система национального воспроизводства сегодня неотделима от механизма инновационного рынка, и нововведения играют все возрастающую роль в экономическом процессе. Внедрение инноваций в любую из сторон экономической жизни общества порождает ожидание их скорой отдачи, достижения справедливого экономического эффекта, наращивания конкурентных преимуществ. Кроме того, важнейшим инструментом для повышения современной конкурентоспособности является не только и не столько использование инноваций в повседневной жизни организации и общества, но также активное привлечение в нее информационных технологий. Современная экономическая среда неотрывно связана с применением средств IT.

Общим недостатком наиболее известных подходов (Й. Шумпетер, М. Портер, Р. Солоу - Т. Сван, В.В.Леонтьев, У.Нордхаус К. Шелл, Д. Йоргенсен, С.А. Дятлов, Г.А. Унтура, А.Е. Когут и др.) к определению влияния инноваций и информационных технологий на развитие экономической системы является отсутствие действенного и однозначного подхода к определению взаимовлияния информационной и инновационной составляющей региональной экономической подсистемы и остальных ключе- вых ее элементов на функционирование экономики.

В этой связи представляется актуальным предложить действенный имитационный инструментарий, позволяющий органично вписать стоимостные, количественные и качественные характеристики рынка инноваций и рынка информационных технологий в современную экономическую систему, что может дать возможность полнее понять природу, взаимосвязь и мультипликативные волновые эффекты взаимовлияния выпуска инновационной продукции, затрат на IT, инфляции, занятости, задействованности основных производственных фондов, инвестиционных процессов на объем выпуска инновационной продукции и использование информационных технологий. Предлагаемый имитационный инструментарий позволяет включить в системную функциональную модель рыночной экономики механизм рынка инноваций и рынка информационных технологий.

Под рынком инноваций мы будем подразумевать взаимодействие объема разрабатываемых и внедряемых инноваций и объема их потребления. Товар на данном рынке - не что иное, как инновации различного характера. Объектом обмена в сфере инновационной деятельности могут быть результаты любой стадии реализации инновационного процесса: фундаментальных исследований, прикладных исследований, освоения, разработки. Рынок инноваций пред- 
ставим количеством инновационных предприятий в качестве количественного показателя и объемом выпуска инновационной продукции в качестве стоимостного показателя.

Рынок информационных технологий подразумевает взаимодействие объема разрабатываемых информационных технологий и уровня инвестиций в них. В российских условиях такой продукт, как информационные технологии является малопрозрачным и трудно определимым. Учитывая данное обстоятельство, мы считаем необходимым рассчитывать взаимодействие на рынке IT соотношением уровня затрат в IT-производство и количества предприятий, использующих информационные технологии в своей деятельности. Отметим, что данный выбор обусловлен довольно сложной определимостью IT-продукции и скудным набором статистических данных, позволяющих построить системную функциональную модель рыночной экономики с учетом факторов рынка IT.

Выявленные новые межрыночные пространства можно условно разбить на три основные группы: инновационное межрыночное пространство, IT-пространство, инновационно-информационное межрыночное пространство (рисунке 1).

Инновационное межрыночное пространство представляет собой область взаимодействия и взаимовлияния рынка инноваций и классических рынков в экономической системе.

IT-пространство формируется вследствие взаимовлияния и, проистекающей из него взаимозависимости рынка информационных технологий и классических рынков.

Инновационно-информационное межрыночное пространство образуется в зоне взаимодействия и взаимовлияния рынка инноваций и рынка информационных технологий.

Функционирование инновационного межрыночного сегмента определяется взаимодействием следующих выявленных новых факторов взаимовлияния рынка инноваций и классических рынков.

Первый межрыночный сегмент получил название инновационной отдачи основных производственных фондов и представляет собой взаимовлияние количественного показателя рынка капиталов (стоимость ОПФ) и стоимостного показателя рынка инноваций (объем выпуска инновационной продукции).

Следующий новый полученный сегмент - влияние цен на инновации, описывающий взаимозависимость выпуска инновационной продукции и уровня инфляции, и являющийся следствием взаимодействия рынка инноваций и товарного рынка.

Такой новый межрыночный сегмент, как производительность инновационного труда определяет взаимовлияние количества занятых и объема выпуска инновационной продукции.

Зависимость инновации и мотивации, так же входящая в число новых межрыночных сегментов, представляет собой взаимодействие количественного показателя рынка инноваций - количества инновационных предприятий и стоимостного показателя рынка труда - уровня заработной платы.

Еще один новый сегмент в инновационном межрыночном пространстве - влияние числа инновационных предприятий на объемы производства совокупного продукта образуется в результате взаимодействия количественного показателя рынка инноваций (количество инновационных предприятий) и стоимостного показателя товарного рынка (объем произведенной продукции).

Последний новый межрыночный сегмент в инновационном межрыночном пространстве - влияние стоимости капитала на количество предприятий, использующих инновации.

Анализ формирования и функционирования инновационного межрыночного пространства позволит определить особенности воспроизводственного процесса инноваций как региона, так и страны, дать экономико-математическое описание выявленных взаимозависимостей и сделать соответствующие рекомендации в части формулирования основных положений экономической политики.

Разработка и построение системной функциональной многосекторной модели экономики с учетом рынка инноваций и рынка информационных технологий позволило выявить наряду с инновационным межрыночным пространством еще один важнейший такой элемент - IT-пространство [1, 57-80]. IT-пространство образуется вследствие функционирования и взаимовлияния рынка информационных технологий (IT-рынка) и классических рынков факторов производства.

Разработанная новая концепция определения взаимовлияния рынка информационных технологий и классических рынков описывает 

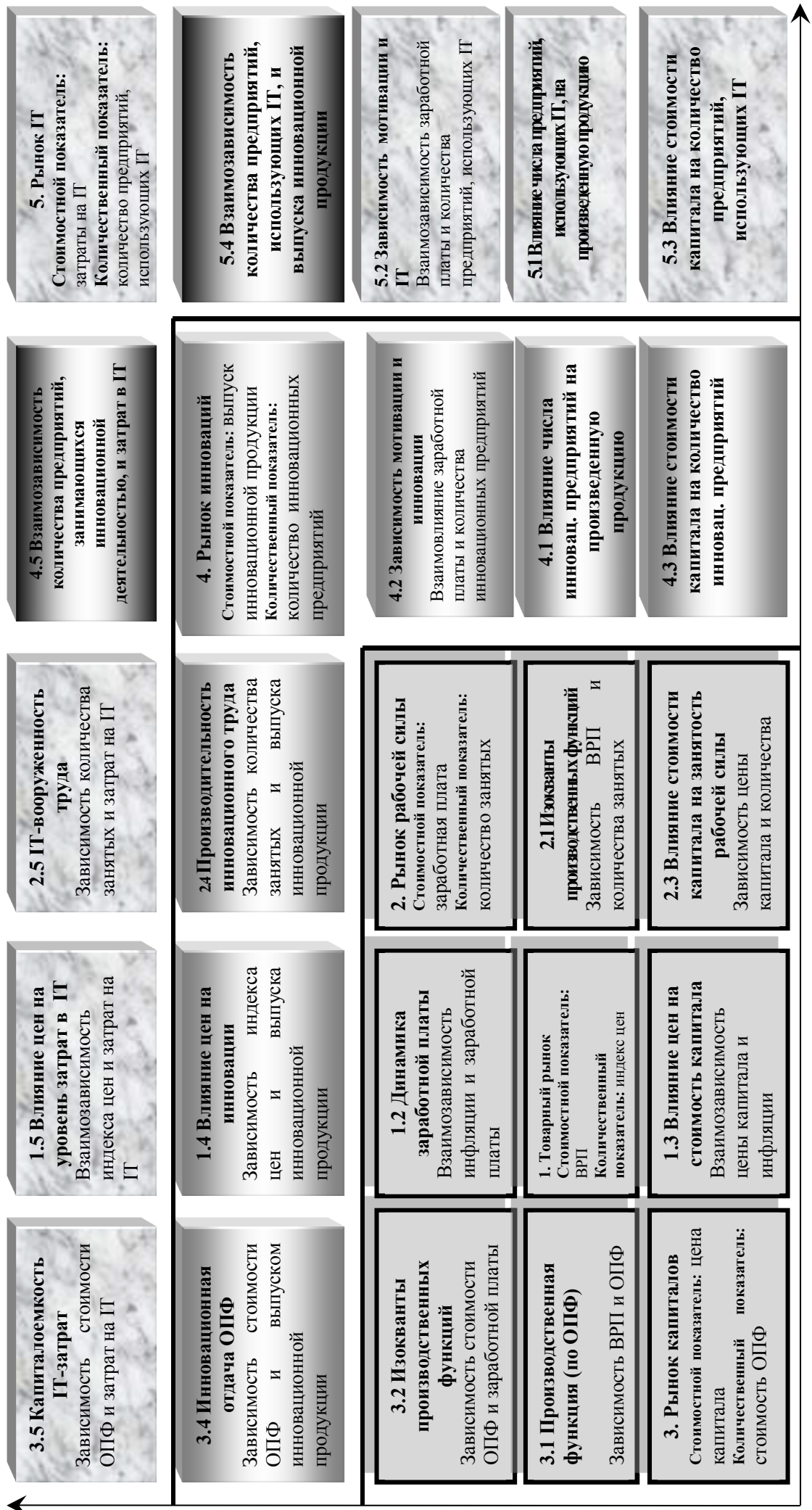

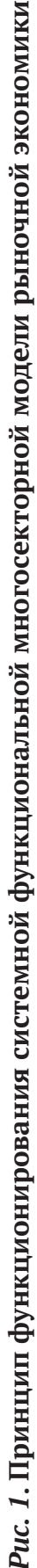

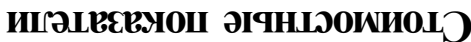


взаимодействие следующих обнаруженных новых факторов:

1. Капиталоемкость ІТ-затрат. Он представляет собой взаимовлияние количественного показателя рынка капиталов (стоимость ОПФ) и стоимостного показателя рынка информационных технологий (затраты на информационные технологии).

2. Взаимовлияние индекса цен и затрат на IT. Как и в инновационном пространстве, данный сегмент является следствием взаимодействия товарного рынка и рынка информационных технологий. Товарный рынок здесь представлен количественным показателем уровнем инфляции, а IT-рынок - его стоимостным показателем - объемом затрат на IT.

3. IT-вооруженность труда представляет собой зависимость количества занятых и затрат на IT, являющихся количественным показателем рынка труда и стоимостным показателем рынка информационных технологий соответственно.

4. Взаимозависимость мотивации и количества предприятий, использующих IT,- это взаимовлияние количества предприятий, использующих информационные технологии (количественный показатель IT-рынка), и уровня заработной платы (стоимостной показатель рынка труда);

5. Влияние стоимости капитала на количество предприятий, использующих IT-межрыночный сегмент, представляющий собой взаимовлияние количественного показателя рынка информационных технологий и стоимостного показателя рынка капиталов.

6. влияние применения информационных технологий на объемы производства совокупного продукта отражает результаты взаимодействия рынка информационных технологий (и его количественного показателя- количество предприятий, использующих IT) и товарного рынка (и его стоимостного показателя - совокупного объема произведенной продукции).

Анализ и оценка выявленного нового межрыночного сегмента с участием рынка информационных технологий позволят сделать вывод о траектории развития рынков информационных технологий в национальной и региональной экономике. Построение модифицированной включением IT-рынка системной модели экономики Российской Федерации сделает возможным выявление более устойчивого взаимовлияние рынка капитала и IT-рынка, чем аналогичное взаимодействие в региональной экономике.

\section{Библиографический список:}

1. Гарипова Е.Н., Сафиуллин М.Р. Оценка и прогнозирование влияния инноваций и информационных технологий на макропараметры развития в современной экономике. Казань. 2015. 89 с

2. Дятлов С.А., Марьяненко В.П. Теоретико-методологические основы анализа национальной инновационной системы // Экономика образования. 2012. № 3, с. 73-80.

3. История экономических учений: учебное пособие для студентов / Под ред. В. Автономова. Москва. 2004. $784 \mathrm{c}$.

4. ̆оргенсен Д., Филлипс, М. Дискурс-анализ: теория и метод / пер. с англ. под ред. А.А. Киселевой. Харьков. 2004. 336 c.

5. Канева М.А., Унтура Г.А. Взаимосвязь НИОКР, перетоков знаний и динамики экономического роста регионов России // Регион: экономика и социология. 2017. № 1, с. 78-100.

6. Когут A.E., Рохчин В.Е. Информационные основы регионального социально-экономического мониторинга. Санкт-Петербург. 1995. 180 с.

7. Леонтьев В.В. Избранные произведения. Москва. 2006-2007. 407 с.

8. Сафиуллин М.Р., Зайнуллина М.Р., Гарипова Е.Н. Современные пропорции и характеристики макроэкономической модели развития Республики Татарстан. Казань. 2016. 58 с

9. Солоу Р.М. Теория роста / Панорама экономической мысли конца XX столетия. Под ред. Д. Гринауэя, М. Блини, И. Стюарта. Пер. с англ, под ред. В.С. Автономова. Том 1. Санкт-Петербург. 2002. 668 с.

10. Туккель И.Л., Яшин С.Н., Кошелев Е.В., Макаров С.А. Экономика и финансовое обеспечение инновационной деятельности. Санкт-Петербург. 2011.-240 с.

11. Шумпетер Й. Теория экономического развития. Москва. 2007.864 с. 